Psychology of Language and Communication 2022, Vol. 26, No. 1

Sciendo

DOI: $10.2478 /$ plc-2022-0003

\author{
Nasimeh Nouhi Jadesi \\ English Department, Salman Farsi University of Kazerun, Iran
}

\title{
Identity markers in the Internet usernames adopted by female users of a Persian public discussion forum: A sociolinguistic analysis
}

\begin{abstract}
Drawing on the feminist poststructuralist perspective, the current study explored the usernames adopted by female users of Ninisite, that is, a Persian discussion forum, and aimed at identifying their identity markers. To this end, a corpus of 947 usernames in Ninisite was compiled. Using thematic analysis, the recurrent themes in the usernames were pinpointed, which led to the identification of six themes as identity markers, namely, gender, religion/ideology, ethnicity, occupation/profession, being humorous, and sense of uniqueness. With regard to the socioculturally unique context of Iran, a continuum of specificity versus generality can be observed in the usernames on Ninisite, with specificity emphasizing differences, sense of uniqueness, and individualization of the users, and generality highlighting neutrality, commonalities, and conventionality.
\end{abstract}

Key words: identity, sociolinguistics, Ninisite, linguistic analysis

Address for correspondence: Nasimeh Nouhi Jadesi, English Department, Salman Farsi University of Kazerun, Kazerun, Iran.

E-mail: n.nuhi@kazerunsfu.ac.ir

This is an open access article licensed under the CC BY NC ND 4.0 License. 
Cyberspace has permeated our lives in various forms. An online forum, or a message board, is an online discussion site where people can hold conversations in the form of posted messages. The online public forums have enabled people around the globe to exploit the convenience and freedom offered by them to freely express themselves and also explore others' self-expressions (Memari et al, 2017).

It is obligatory for users of public forums to create or adopt a name upon registering on the forum and creating an account. Zhou et al. (2021) describe usernames as "self-reflective titles in the online community" (p. 2). Usernames, among other things, function as identity badges for the users while they interact and socialize online. As Aldrin (2014) stated: "choosing a certain name then, or choosing to act in a certain way during the process of naming, implies choosing which social attributes, values, groups and positions one wishes to be associated with and which ones one wishes to be dissociated from" (p. 395).

This leads to a plethora of usernames with varying degrees of creativity, including diverse associations and connotations. This diversity offers an opportunity for linguists or psychology and social science researchers and experts to investigate how a person can develop multiple identities and how their usernames convey a sense of who they are, just as our real name reveals some information about our social, cultural, or religious background. Hence, usernames can be conceived of as "a kind of substitute for the face and the body" (Subrahmanyam et al., 2004, p. 660). As Aggarwal (2016) contends, usernames are critical in terms of facilitating online interactions, as they act as embodiments of the impressions made about the users, which will determine the quality and nature of the online interaction the users engage in. Rodan et al. (2010) believe that the usernames integrate into the users' identity and lead to emotional recognition in users, determining how the flow of communication is established. It is conceivable that adopting a username is not done arbitrarily. Rather, it can be perceived as a tool for self-representation with a strong personal purpose (Shebanova \& Yablonska, 2019).

English terms for the names adopted by Internet users are diverse: "alias," "handle," "login/login name," "nick/nickname," "user ID," "username," "account name," "aka," "ID/identifier," and "screen name" (Aleksiejuk 2016a, 2016b). In this article, following Aleksiejuk (2017), the term username is used to refer to the names that users adopt upon registering in different platforms, as it is a widely known term. Also as Aleksiejuk (2017) asserts, "in contrast to such terms as nickname or pseudonym, [username] has not been allocated to designate other names than those used online" (p. 46).

From a poststructuralist perspective, usernames may be considered as constitutive of the self, not merely substitutive of the physical features. Interacting in virtual arenas deprives one of the offline interactions where some understanding of who one is communicating with is possible. In such circumstances, adopting a name for oneself - that is, adopting a username - does convey some information about who we are or what our perceptions about ourselves are. Consequently, 


\section{ADOPTED BY FEMALE USERS}

usernames adopted by public forum users can be regarded as emblems of their selfconstruction, which justifies the exploration of the types of usernames adopted. The approach underpinning this study is the poststructuralist movement, which is concerned with language as a social phenomenon. In this view, language is constantly shifting as a response to the purpose and context (Weedon, 1997). This study is also informed by a feminist poststructuralist perspective (Baxter, 2000), a subdiscipline of the broad poststructuralist movement, to explore how discourse affects meanings related to gender, sexuality, and identity (Foucault 1972, 1978).

In this study, it was hypothesized that by analyzing the usernames adopted by the users of Ninisite, a Persian public discussion forum specifically for women, the underlying themes that characterize their identities could be extracted. Hence, this study attempted to answer the following research question: What themes underlie the usernames adopted by the users of Ninisite?

\section{Literature Overview}

Normally, users of social media enact diverse multiple identities in the virtual world, which has been associated with identity development. Studies suggest that the kind of use made of social media depends on factors such as ethnicity or race (e.g., Grasmuck et al., 2009; Subramanian 2010; Michikyan et al., 2015), gender (e.g., Manago et al., 2008), and site features (e.g., Tynes et al., 2011).

Current studies have exhibited that the users of a public forum cognitively identify themselves as members of the online community and absorb the ideas and practices of other members as their own (Prentice et al. 2019; Yoshida et al., 2015). In the same vein, Badrinarayanan et al. (2015) concluded that group identification can result in members' growing participation and contribution to the online community.

Zhou et al.(2021) believe that usernames not only influence others but also affect the person who chose them since they adapt to the adopted character that the username signifies and attempts to match it. As a unique feature of online communities, users can explore different selves, inhabit different identities, and enrich their perceptions of themselves by engaging in various interactions. Subrahmanyam et al. (2006) investigated online teen chat rooms and analyzed 500 usernames. They found that in many respects, users' online usernames reflected their offline selves. In the following section, the studies related to the subject under investigation are presented.

\section{Internet Onomastics}

Kersten and Lotze (2021) explored the use and function of anthroponyms and other names in online contexts. They analyzed the data collected as part of a wider study of usernames across 14 languages (Schlobinski \& Siever, 2018) and categorized the underlying self-naming practices into five major principles in 
accordance with the principles of identity construction discussed in Bucholtz and Hall (2005). The principles identified and exemplified by the authors included: choosing a name is a dynamic and negotiated process; choosing a name refers to a diachronic change in internet-based conventions and thus also to a change in the relevant criteria for identity work; name choice is based on the principle of values and the aesthetic sense of the community; names are chosen with regard to a range of relevant decision criteria which are on a continuum, such as anonymity versus authenticity; and name choice can only be partially experienced, interpreted, and controlled. Prior to this research, Kersten and Lotze (2020) had discussed self-naming as a conscious choice of usernames and a form of facework. They clustered usernames together with their motivations of name choice along three continua: authenticity and anonymity, individualization and group convergence, and phonic and graphic aesthetics. Following that, they posited the principle of monoreferentiality, the principle of self-representation, the principle of authentication versus anonymization, and the principle of individualization versus group convergence as the four principles of online identity construction. The authors affirmed that these four principles are not mutually exclusive and they mirror human identity work on various levels: unity with oneself and a monoreferential name, self-expression of partial identities, authentication as a rational agent, and group behavior. However, the authors admit that depending on the nature of the community of practice and the variety of the affordances offered by different platforms, other strategies might also be at work.

Drawing on Sjöblom's (2006) functional-semantic analysis model, Hämäläinen (2013) explored the usernames adopted by users of a Finnish online gaming community and suggested that usernames can be divided into two functionally different parts: the identifying part, which functions as the foundation of username and normally is its lingual part, and sometimes a supplementary part, which distinguishes the name apart from other similar ones. He also contended that only $60 \%$ of usernames are capitalized.

\section{Usernames in Different Sociocultural Contexts}

Investigating the usernames created or adopted in different sociocultural contexts and different platforms (WeChat, Facebook, Twitter, etc.) can contribute to and enrich our understanding of the sociocultural dimension of identities (Olivier, 2014). Hence, the studies carried out on usernames in different geographical areas are presented here. One such attempt was the study by Hassa (2012), who analyzed the usernames adopted by Moroccan chat room users. She found different patterns in creating usernames and diverse cultures like Spanish, AngloSaxon, and French cultures informing the usernames created by the users in addition to the local cultural features. She pointed out that the usernames reflect the users experiencing a fluctuation between a traditional and local Muslim Moroccan identity and a tendency to assimilate with the modern global world. 


\section{ADOPTED BY FEMALE USERS}

Two studies were carried out in China. Xu et al. (2020), using an onomastic lens, examined 501 WeChat usernames which were collected through an online survey. The authors investigated the categories emerging from the name corpus and explored the justifications for selecting each of these categories. Afterwards, they analyzed the sociocultural factors informing the usernames. Taking Chinese culture into consideration, they referred to online discourse and acquaintance networks as influential in username adoption and to their contribution to these context-specific naming practice. The findings indicated that the participants tended to negotiate their naming practices to deal with the tension between selfprotection and self-presentation. Another study which was carried out in the same context by Zhou et al. (2021) aimed to explore the users' motivations for choosing their usernames. They collected 394 sample usernames from a Chinese online community so as to test their research model. They identified three factors as influential in terms of username choice, namely, virtual exploration, social navigation, and contextual adaptation, which are believed to have direct effects on the way the internet users of the forum interact socially. The above-mentioned studies carried out in China reflect an inclination toward the nature and affordances available for the online interactions, which complements the results obtained by Hassa (2012), who found that the usernames were mostly culturally-driven.

Another geographically unique domain was explored by Shafie et al. (2012), who took the perspective of gender differences and explored the usernames adopted by 185 Malay university students' Facebook profiles, which, as the authors claim, is the most popular social network site among university students in Malaysia. The findings indicate that the 64 female users and 19 male users preferred creative variations of their real names as their Facebook usernames. On the other hand, 39 male users and 55 female users preferred to use their real names. The male users declared that they were more comfortable and less inhibitive in using their real name in online settings, as they were more comfortable with revealing their true self online. The results indicated that values such as peer perception, social connection, popularity, and the self domains may underlie the choice of the usernames by these users

\section{Usernames in Special Audience Forums}

Some of the public discussion forums are specifically designed for special groups of users, for instance, individuals with certain physical conditions. A prime example was shown by Stommel (2007), who examined how usernames used by participants in a German forum designed for eating disorders can be perceived as a displayer of identity. The author qualitatively analyzed 83 usernames of the Hungrig-Online forum. The results indicated that an interdependent intricacy of denotational and stereotypical features along with well-known referents of the names can characterize identities. The persona attributes informing the usernames included smallness, weightlessness, childishness, negative self-evaluation, and 
depression. However, other persona attributes like self-confidence were also visible in the usernames. The author contended that several of these attributes can be linked to multifaceted femininity. Likewise, Rodan et al. (2011) examined the difficulties faced by users of HeartNET, which is a public online forum for individuals with a heart condition, who, as users of other platforms, are faced with the challenge of anonymity. The authors first established four categories of engagement describing the participants of public online communities. Then, they contended that authenticity does not necessarily entail the provision of identifying information. They argued that usernames themselves can serve as a tool to obtain authenticity. That is, using the same username over time facilitates authenticity, as they can exhibit the member's persona and lead to emotional recognition. Using the same username over time can facilitate authentic exchanges.

\section{Method}

\section{Context of the Study}

The data used for this study was collected from Ninisite, an Iranian public forum. The majority of users are/identify as women, the medium of communication is primarily Persian. and the company's headquarters are in Tehran, Iran. The website is designed with the purpose of addressing health and parenting issues faced by women. Rahmani (2021) - as one of Ninisite managers - stated that the 13-year-old website enjoys a traffic of over 800 thousand visits per day and over 80 thousands posts are in over 3 thousand topics are created each day in the website by Persian speaking women all over the world. Based on Alexa rankings, Ninisite is the 310th (on October 8th 2021) in Iran, and over $81 \%$ of the users of Ninisite are from Iran, $12.6 \%$ are from the US, and $1.1 \%$ are from Canada. As shown in their profile bios, the majority of users are women. Having registered, the users are allowed to create topics, like, or comment on others' posts. As nonusers, they can only read the topics created by others and do not have the permission to create a topic or leave a comment. In order to be a user, the individual must fill out an online registration form and adopt a username. A glance at the usernames adopted by the users of Ninisite reveals that theyare very telling and can be perceived as a reflection of the users' identities.

Although Ninisite is mostly dependent on the users to create content, the forum does not offer much technological affordance to the users to engage in more interactive activities which are mostly features of Web 2.0 , such as sending links to other users who are "friends," membership in groups of various kinds, or subscriptions or RSS feeds of updates from other users. Hence, Ninisite can be considered mostly as a Web 1.0 site. As such, it can be inferred that the users do not feel an obligation for authentication. Hence, there is still anonymity and equality in the usernames, which allows an interpretation of usernames in terms of identity reflection. 


\section{ADOPTED BY FEMALE USERS}

Ninisite, like most other public forums, sets some restrictions on the adoption of a username. These include: (a) usernames not being against social or ethical norms, such as pejorative or offensive words (although an explicit clarification of what offensive or pejorative is has not been provided by the website administrators), (b) usernames not being identical to or resembling those of the website administrators (since some of the admins - called "Niniyar," which literally means "the helpers of Ninisite" - have the right to post and comment as regulatory and controlling figures), (c) once a username is adopted, the user cannot change it unless they obtain the admin approval, which is usually not granted. The strict restriction regarding changing one's username is done under the argument that other users may have difficulty recognizing the user if they change their usernames. (d) The username should be unique. The obligation to choose a unique username, which is called enforced monoreferentiality, that is, having only one referent (Kersten \& Lotze, 2021), is observed in different platforms and is demanded to ensure that no two users have identical username. Monoreferentiality is practiced in the construction of usernames by the users through several strategies such as adding numbers, repeating some letters, inserting symbols, or substituting some letters with similar numbers and symbols (De Hoyos, 2020).

Observing these restrictions, other possible words or strings of words are permitted, whether without a meaning or with several meanings. Within the restrictions outlined above, users are free to build their virtual identity as they wish. The very fact that they are not permitted to change their username once selected makes the users choose them with utmost care and the username they adopt is significant to them. A piece of evidence which proves this claim is observed when a user is suspended due to violation of the website regulations. On their second attempt to adopt a new username, they take some strategies to maintain their previous username. Some may use their previous username with words like "former," creating usernames like رها كلى سابق /Raha goli-ye- sabeq/ literally meaning "former dear Raha," or adding words like suspended, exploded, (which is a term used by the forum users to refer to the imposed removal of a user due to violation of the forum regulation), and so forth, in usernames like بانومنيز دوبار تركيد /banoo Manij do bar terekideh/ literally meaning "Lady Manij, exploded twice." Some others may use numbers to denote that they are the same user, for instance, زيناكلمن /Zhina gol-e man/ will be 2 زيناكلمن/Zhina gol-e man 2/, implying that she is the same user. These strategies are taken by the users to remain recognizable by other users and feel they are still a part of the community of practice they belong to. Such practices show how significant their usernames are to the users since they identify with their usernames. The above-mentioned context information is utilized throughout this study to support the analyses made further. 


\section{Data Collection}

The website is compartmentalized into different areas. For the sake of this study, only the discussion section where the users can create new topics, comment on the topics, or simply read the created topics was selected. In the discussion forum of the website, the recently created topics are shown. The new topics replace the old ones which become accessible only through the search engine of the website.

To collect the sample usernames from the website, the usernames of the users who had created a topic between 6 to $8 \mathrm{PM}$ in ten successive days were recorded. This time span was selected since it is a high traffic time for the website, and many users create new topics or leave posts on them. In each day, approximately, 80 to 90 topics were created and the usernames of the topic starters were recorded, resulting in a corpus of 963 usernames. Repeating usernames were excluded, reducing the final corpus of the analysis to 947 usernames. This approach was adopted since there is no list of all users' usernames available in the website and the administrators did not respond when contacted to provide such a list.

\section{Data Analysis}

In line with the research question guiding this study, there were two analysis phases. In the first phase, a linguistic analysis of the corpus in terms of the word and phrase types was carried out. The framework used by Stommel (2007), which had similar focus and scope as the current study was applied. This framework included items such as commonly used names, novel formations, noun and noun phrases, adjectives, verb forms, and exclamations. In the current study, noun phrases, usernames containing adjectives, sentences, onomatopoeic words, and nondecodable and noncategorizable words were employed as a classificatory framework for the linguistic analysis of the usernames. In the second phase, the repeating themes in the usernames were detected. The corpus was read and reread by the author and the recurrent themes which signified and characterized identity traits of the users were pinpointed.

\section{Ethical Considerations}

In the website rules and regulation section, it is explicitly mentioned that any research carried out on the Ninisite content is allowed as long as the source of the data, that is, the website name is reported. Hence, no consent was needed to be obtained from the users whose usernames have been examined here.

Another issue observed in this study was the fact that in order not to unintentionally disclose information about the users of the website, only their usernames, and not their utterances in the topics, should be the subject of analysis. 


\section{Results}

\section{Linguistic Analysis of the Usernames in Ninisite}

The linguistic analysis of the collected username corpus led to a categorization of the main word and phrase types of the usernames adopted by Ninisite users. Table 1 shows the list of categories of the word and phrase types. The number and percentage of each category type have been provided.

Anthroponyms were the largest category, comprising nearly half of the corpus. They were mostly the users' own real names and sometimes their loved ones', such as their children's. The users used either their real names with no modifications, and sometimes in combination with other words or numbers, or they have made some changes in their real names. The reason for these modifications might have been twofold. First, they have intended to avoid duplicating an already existing username. Secondly, as explained later, it seems they have wished to make their usernames specific and unique. The modifications included inserting numbers or symbols into their real names, deleting some letters or syllables of their real names, changing the order of the letters of their real names, repeating some letters or syllables of their real names, or other creative techniques. The same practice was reported by Hassa (2012), where about 50 percent of the usernames included common Moroccan first name or surnames. This figure was reported to be 32.3 in the study by Xu et al. (2020), who also reported similar modifications made in Chinese names adopted as usernames in WeChat. Aleksiejuk (2016a, 2016b) also provided detailed account of similar modifications in the usernames.

The second largest category was appellative usernames. The noun forms appearing in the usernames belonged to different notions, areas and concepts. A noticeable recurrent notion observed in the usernames was "famous characters." By famous characters, either real famous individuals or imaginary, literary work and visual art characters are meant. Regarding the real characters, the diversity observed in the choice of characters as usernames was outstanding. Both Iranian

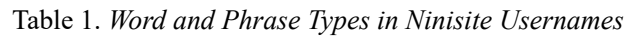

\begin{tabular}{cccc}
\hline \multicolumn{2}{c}{ Word and phrase type } & Number & Percentage \\
\hline Anthroponyms & Nonfamous characters & 420 & $48.8 \%$ \\
\cline { 2 - 4 } & Famous characters & 31 & $3.6 \%$ \\
Appellative usernames & 149 & $17.3 \%$ \\
Usernames containing & 130 & $15.1 \%$ \\
adjectives & & \\
Nondecodable and & 81 & $9.4 \%$ \\
noncategorizable & 46 & $5.3 \%$ \\
Sentences & 2 & $0.24 \%$ \\
Onomatopoeic words & & \\
\hline
\end{tabular}


and non-Iranian real famous characters have been selected as usernames or part of the usernames. Shajarian, who was a recently deceased popular singer, has been adopted as a username only one day after his death by one of the users, signifying the influence of the celebrities on the minds of the individuals as an instance of the influence of a sociocultural context. A plethora of non-Iranian celebrities like singers, authors, and so forth, have also been selected by the users as their usernames. The following are a few examples of non-Iranian famous characters:

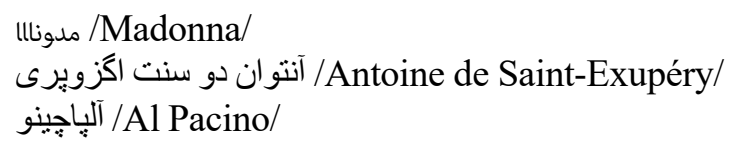

The third largest category was usernames that included adjectives. Some of the usernames adopted were larger linguistic units, namely, sentences. Both declarative and imperative sentences have been used as usernames, which constituted about $5 \%$ of the corpus. A few examples include:

/man be zudi madar mishavam/I will be a mom soon 年/madar shouharetunam Aqdas/I'm Aqdas, your mother-in-law

kolli arezu daram/I have so many dreams

Onomatopoeic words mostly reflecting different feelings or sounds were also evident in the corpus, with words like ملج ملو ت /Malach Molooch/, which is a sound made while slurping food and اووف /Oof/, which is a sound produced when one is either injured or shocked, belonged to this category. These two were the only instances seen in the corpus, contributing a negligible $0.24 \%$ of the data.

Finally, about $10 \%$ of the usernames were either nondecodable or noncategorizable. "Nondecodable" meant that the usernames were either nonexisting words and phrases, or they were combinations of other words creating nondecodablelexicalitems, forexample,"gddhy77." "Noncategorizable"usernames were usernames which did not fit into these categories, yet there was not a sufficient number of them to be subsumed under a new category. However, some usernames which may seem nondecodable by outsiders can be quite decipherable by users of the forum who possess a shared understanding about the culture of the community of practice they engage in. In this categorization, the author has counted only the usernames that are nondecipherable even in light of the common naming practice of Ninisite (with the author being an active user of the forum and familiar with its naming practices) as nondecodable. 


\section{ADOPTED BY FEMALE USERS}

\section{Thematic Analysis of the Usernames in Ninisite}

\section{Gender as an Identity Marker}

Gender has been a recurrent theme in the usernames adopted by the users of Ninisite. Femininity has been marked through multiple strategies in the usernames. Following Alford's (1978, pp. 65-68, qtd. in Aleksiejuk, 2017) name sex typing across the cultures, gender can be traced in the Ninisite usernames through semantic meaning, convention and affixation. Semantic meaning is observable in usernames with words referring to nature, for instance, "star," "spring," and "flower," which signify delicacy, beauty, and so forth, and connote femininity. The username شكوفه بهارى /shekoofeh bahari/ is such an example, which literally means "spring blossom." With respect to affixation, in Persian, some female proper nouns which are of Arabic origin receive a final silent $h$ pronounced /e/, such as "Hamideh," which is the feminine form of the male version "Hamid."Femininity was also implied through conventional female names. These were either given names such as "Sara," "Goli," and so forth, or usernames without a given name but using words that implied gender, including usernames containing words such as خانم/khanom/, بانو/banoo/, all meaning "woman," "lady," and دختر /Dokhtar/ meaning "girl." In rare cases the English form girl has also been used to indicate gender. Although very rare, some male users have also followed the same practice and have used words like $د ر د$ /mard/ meaning "man" and بپر/pesar/ meaning "boy," in their usernames to indicate masculinity. English address terms indicating gender have also been used, for example, "Ms.-Noonoosh" or "Mrs_Shiva."

\section{Religion/Ideology as an Identity Marker}

Since most Iranian are religious (Muslims), it is no surprise that religion can be influential in their identity. Accordingly, ideologically expressive usernames are common in the Ninisite discussion forum, functioning as markers of the users' religious inclinations and adherence $t$ or acceptance of some ideologies.

Users used diverse strategies to characterize their religion or ideology in the community of practice they are interacting in. One strategy involves making a direct reference to words reflecting their religion and ideology. For example, the word سادات or سيده /seyede/, /sadat/, which are feminine Arabic address terms signifying that the users are descendants of the Prophet Mohammad, are frequent in some of the usernames. Alternatively, the word خدا /khoda/ meaning "God"has been used in some usernames in phrases like ياد خدا/ خدا /yad-e- khoda/ meaning / هديه خدا hedi-ye-khoda/, meaning "God's gift" (probably meaning children) or هستاجر خدا /mosta'jer-e- khoda/, which means "God's tenant." 
Another strategy involves making more implicit and indirect references which are only decodable by people having the same shared religious. The ياس username فـك /fadak/, which is the name of a village in Saudi Arabia, or كبود /yas-e kabud,/, literally meaning "the bruised Jasmine," are associated with Hazrat Zahra_-Prophet Mohammad's daughter-who is respected by Muslims and considered to be a perfect model for Muslim women. These two usernames refer to a historical event which is religiously significant to Muslims.

Aside from references to religion, some of the usernames reflected other ideologies. The eight-year war with Iraq caused thousands of casualties. Hence, usernames containing the word shahid (meaning "martyr") are abundant. The username شهيد كمنام/shahid-e-gomnam/, which refers to those victims who have not been identified and have been buried with no name on their tombstone is one such reflection of the user's ideology. Another instance is سرداردلها دلتتكتيم/sardare-delha-deltangetim/, which reads as "our hearts' hero, we are missing you," referring to Qasem Soleimani, an influential high-rank military general venerated by many Iranians. Such usernames characterize adherence and acceptance of the Islamic government of Iran and supporting its policies and practices.

Although some areas of Iran are occupied by Sunni Muslims, references to Sunni Islam or other religions in the usernames were rare. The reason might be the fact that the official state religion in Iran is Shia Islam.

As Hassa (2012) indicated, referring to one's religion may serve two functions. First, "informing the chat room community that conduct will need to conform (at least at first) to Muslim religious principles" (p. 206). Second, it may help to establish a sense of ingroup solidarity or intimacy among the group members, pinpointing the desire to affiliate through shared sociocultural practices. Living in a predominantly Muslim society, the users tend to reflect their religion or ideology in their usernames.

\section{Ethnicity as an Identity Marker}

A point deserving attention was the tendency of the users to use both Persian and English in creating usernames. In some cases, even a combination of the two languages was observed. كkimials is a username in which the user has spelled her given name Kimia with both English and Persian orthography, in a way that the English form is inserted inside the Persian form. This unique, playful manner of the two languages was prevalent. Such hybrid use of languages has also been observed in other studies (Aleksiejuk, 2017; Stommel, 2007). Aleksiejuk (2017) contended that language diversity in usernames is greater than in conversations. She argued that it is doubtful that these usernames will be read by the audience as expressions of national identities; it is more likely that they will be seen as "a reflection of the influence of English on Internet communication globally, or the contemporary trend to use language" (p. 96).

A more interesting observation is that not only different languages, but also 


\section{ADOPTED BY FEMALE USERS}

dialects are reflected in the usernames adopted. There are a variety of ethnicities and language backgrounds among Persian speakers. A tendency observed in the usernames was injecting some information about ethnic background, which made it possible to ascertain where the users are geographically located, or what ethnic background they belong to. This indication was made mostly through two techniques. The first was to directly mention their ethnic background or their place of residence in their usernames, resulting in usernames like دختر ترك/dokhtartork/ meaning "Turk girl." In these instances, the usernames evidently include the ethnicity marker with some variation on the language employed, combining it with other identity markers such as femininity markers reflected in the word "girl."

Second, a subtle way to indicate ethnicity or linguistic background -which was used less frequently but was more creative- was using a linguistic feature of Persian, mostly dialects, as an identity maker. Oral features of a dialect are applied to usernames presented in a textual form, resulting in innovative and interesting usernames. That is, the usernames adopted in this way do not include a direct indication of ethnicity. Two examples are presented here. The first instance is the username دمي؟ى/dampey/ which, literally means "slippers" and is written and pronounced as دميايى /dampaee/ in standard Persian. However, دميى is written in the Lorish dialect which is practiced mostly in central and western regions of Iran. The username دمبى /dampey/ in itself is not understandable by non-Lores and may be taken as a novel formation of a username, and hence nondecodable. To avoid such misperception, the user owning this username has set a picture of a pair of slippers as her profile picture.

Another example of the application of one's dialect in adopting and creating usernames, which helps one be identified with a certain ethnicity is the username آز آزداها واراد مى شود /azhdaha varad mishavad/. This username literally means "the dragon is entering." In standard Persian, this sentence is written as ازدهاو وارد مئ شود / and pronounced as /ezhdeha vared mishavad/. The difference between the standard pronunciation and the one in this username reflects a tendency in Turkish to change short vowels to long vowels, which is absent in Persian. This languagespecific feature has been employed by the user in the username she has adopted.

Another example of using a phonological feature of the dialect spoken by the user in creating usernames is reflected in two usernames: شبو /Shaboo/, resembling Shabnam and Hadisoo, resembling Hadis, which are Persian female names. These two Persian female names have been modified and written as they are pronounced in southern dialects of Iran, where there is a tendency among the speakers of these dialects to add a final /oo/ sound to the names in calling people by their names. Additionally, this special case denotes some sense of humor, since this way of addressing someone is not a polite, standard term of address. Hence, the users have attempted to indicate their ethnicity in their username in delicate, innovative manners, exploiting the capacities of language. 


\section{Sense of Belonging as an Identity Marker}

A close analysis of the corpus reveals another theme, namely, a sense of belonging. A multitude of usernames adopted by the users of Ninisite have used some words indicating belonging. This identity indicator was embodied in two different manners. The first was defining oneself in terms of motherhood. A large category of usernames reflecting this sense included words such as مامان or maman, meaning that they define themselves as someone's mother, making usernames like مامان آرسام /maman-e Arsam/ meaning "Arsam's Mom," very prevalent. The word "mom" was accompanied either with an anthroponymic noun such as "Arsam" or some appellatives to refer to their children. Examples of the latter are مامان سه وير انكر /maman-e se virangar/, literally meaning "mom of three terminators" or مامان فندق كوجولو مانو /maman-e fandoq kuchuloo/, literally meaning "mom of a little hazelnut." Sometimes, the word "mom" was used as an address term to refer to the user as a mom, for instance, مامان آرزو" , which literally means "Mummy Arezu," referring to the user named Arezu as the mom.

Secondly, the users also implied this sense of belonging through referring to their loved ones, especially their husbands, fiancés, and so forth. Since having boyfriend is not religiously and culturally accepted in Iran, no direct mention was made of the word "boyfriend" in Ninisite usernames. That is, only legally approved relationships like marriage or culturally accepted ones like formally announced engagements are approved. In the case of users who do have boyfriends, they commonly use the general word love or the name of their loved one in order to refer to the partner and avoid making a direct reference to the type of relationship. Hence, usernames like حديث آقا بهز ادم literally meaning "I'm Mr. Behzad's Hadis," /eshgh-e-aghaeem/, meaning "My man’s love," or ساراى خوشت آقاييم ye-khodash/, meaning "his own Sara" were common. These two inclinations to define oneself in terms of either motherhood or romance might imply that some of the users define or wish to define themselves by who they belong to, and do not identify themselves as independent and autonomous individuals.

\section{Uniqueness as an Identity Marker}

Another tendency in the adoption of usernames on Ninisite has been an inclination on the part of the users to appear special and unique. This was mostly achieved through two techniques. The first was using some words connoting significance, importance, and uniqueness. To exemplify, one can refer to usernames such as فاطى ،خاص/Nati-ye-khas/, meaning "the unique Fati," or نحار_لاكجرى/Negar_lukcheri/, meaning "Negar, the luxurious." In this case, by "the luxurious," the user intends to imply that she is unique and distinct, as she is luxurious and not average. As a selfpromoting but less direct attempt, some users used titles which are mostly suitable for royal figures, like ملكه ملورين /malake-Melorin/, meaning "Melorin, the queen" or مهناب السلطنه Mahtabossaltane/, meaning "Mahtab, the royal lady." 


\section{ADOPTED BY FEMALE USERS}

\section{Being Humorous as an Identity Marker}

Using lexical terms or titles to assume an air of excellence is not the only way to represent significance or uniqueness. In line with the previous theme, adopting humorous usernames can be perceived as a technique by which some users convey a sense of uniqueness. There was a tendency among some of Ninisite users to adopt usernames which are very creative and original. This makes their usernames memorable, resulting in a sense of significance for the users. These novel creations have been more frequent recently, to the extent that it seems that there is a competition among the users to adopt usernames which are as creative as possible. There are even several topics in which the users comment on the most interesting usernames they have seen on the forum. These creative usernames are mostly funny and sometimes ironic. Some of the users even adopt self-effacing usernames. That is, they opt for being distinct through adopting funny usernames at the expense of deprecating oneself. A familiarity with the Persian language and culture is needed to perceive the irony or uniqueness of such usernames.

One such username was بيكان جوانان كوجه ای /Peykan-e-javanan-e-gojei/, literally "red Peikan for the youth," which is one of the first models of automobile produced in Iran and which signified luxury. The red color was mostly favored by the youth of the time. The username صغرى بلنح /Soghra palang/, which literally means "Soghra tiger," is a combination of Soghra, which is a Persian name of Arabic origin meaning "small and of little importance." The name implies a sense of being old-fashioned and is not usually given to children in the modern Iranian naming practice. On the other hand, the word بلنَ/palang/, which literally means "tiger," figuratively, refers to women who have done lots of cosmetic surgeries and usually wear heavy makeup and, consequently, attract a lot of attention. The combination of the two words in the same username is paradoxical and thus ironic.

Another instance was ننه فو لادزره /nane-fooladzereh/, literally meaning "Mom of Fooladzereh." Fooladzereh is the name of a legendary monster and, in Iranian culture, the expression ننه فو لاد زره refers to a husky, ugly, and brazen woman. This expression is usually used to refer to mothers-in-law who tend to annoy their daughters-in-law and meddle with their affairs. The user has adopted this username to sound unique at the expense of being self-effacing or even selfironizing. The username ليوانى در كونى برنج/livani dar guni-ye berenj/, which literally means "a glass in the rice sack," refers to an old practice in some Iranian families where they keep a glass in their rice sack and use it as a measuring cup. Such usernames are heavily culturally-loaded and are specific to Iranian life and culture. Thus, to understand the subtlety and innovations used in creating these usernames entails having a knowledge of the shared cultural values in the context of Iran. That is, considering the impersonal nature of online interactions, usernames seem to be highly related to the social norms and collective self-value behaviors (Silva et al., 2017; Silva \& Topolinski, 2018). This finding is also in line with Hassa (2012), who found that Moroccan usernames tended to convey 
some sense of humor and a playful complicity, which is only decipherable in the light of the shared culture and knowledge. Referring to Lam (2004), Hassa (2012) believed that chat rooms allow for the construction of shared cultural beliefs and values, which justifies why usernames avoid referring to physical attributes and sexuality due to the fact that an explicit reference to sexuality is often frowned upon in Morocco. This evidence demonstrates that Moroccan users appropriate and customize the Internet in accordance with their accepted sociocultural conducts.

As pointed out by Jönsjö (1979), and as evident in the examples elaborated above, a nickname is sometimes "beyond the scope of linguistic analysis" (p. 6) since it entails subjective interpretation and an understanding of the shared sociocultural values and ideological assumptions

\section{Occupation/Profession as an Identity Marker}

Some users have included their jobs or professions in their usernames. Usernames like "English teacher," سايكولوزيست/saikolozhist/, meaning "Psychologist,"خانم

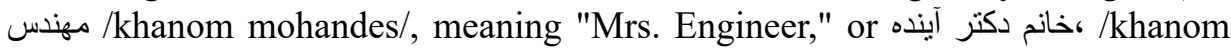
doctor-e-ayande/, meaning "future doctor" belong to this category.

Two justifications seem to be underlying this phenomenon. First, it seems that some users have extended their identity beyond their personal identity and have subsumed their social activities and occupation as part of their social identity. Secondly, some users who are offering some products and services have used the forum as a platform to reach a wider range of potential clients. Seemingly, they have used their job titles as their usernames in order to advertise their businesses. بانو اسكارف banoo scarf/, literally meaning "the scarf lady," was adopted by a user who sells scarves. "English teacher" was another username that signified the user's occupation and advertised it.

It should be noted that since some of the usernames were combinations of words rather than single-word usernames, they could be categorized under different themes. For instance, the gender markers have frequently been coupled with the users' real names, which indicated a reflection of their real world identity, that is, their gender and their real names, leading to usernames such as Maryam banoo/, literally meaning "lady Maryam."

An interesting tendency was observable where some usernames were a combination of two or three themes. For instance, a humorous theme was coupled with famous character, either real or imaginary, and resulted in novel formations such as جارى آنجليناجولى /jari-ye-Angelina Jolie/, meaning "Angelina Jolie's sister in law," آبجى مارلون بر اندو أندو (abji-ye-Marlon Brando/, literally meaning "Marlon Brando's sister," or/namzad-e-Luke-e khoshshans/, which means "Lucky Luke’s fiancée." 


\section{ADOPTED BY FEMALE USERS}

\section{Persona Attributes in Ninisite Usernames}

Kersten and Lotze (2021) clustered the usernames along with their motivations of name choice along three continua: (a) authenticity and anonymity, (b) individualization and group convergence, and (c) phonic and graphic aesthetics. In line with their work, a continuum of specificity versus generality can be observed in the usernames of Ninisite forum, with specificity emphasizing differences, a sense of uniqueness, and individualization of the users, while generality highlighted neutrality, commonalities, and conventions. This is schematically presented in Figure 1.

Some of the users tended to adopt usernames that signified their identity and specific features. The reason might be a desire to be distinct and, at the same, anonymous. Some other users preferred to be perceived as ordinary, common characters, meaning that they opted for anonymity and felt no need to be perceived as unique and recognizable. However, the type of features that most users wished to be identified with were unique to the community of practice they engaged in, which, in turn, is a reflection of the broad cultural and sociolinguistic place they are interacting in.

\section{Concluding Remarks}

The usernames adopted by the users of public forums are not only a prominent tool for the sake of participating in online community activities, but are also an element through which they can characterize, identify, and present themselves. Iran, with its unique cultural and geopolitical features, can influence the motivation for adopting a specific username by female users of a public forum. This study investigated the linguistic tools and techniques employed by female users of a public discussion forum, which is specifically designed for women, in adopting certain usernames and how these linguistic tools and cultural elements can influence their identity.

Generality

No mention of religion

No mention of who one belongs to

No mention of ethnicity/race

Not humorous

No mention of occupation/profession

Not gender-indicative

Specificity

Religious/ideological

Mentioning who you belong to

Ethnic/local

Humorous

Mentioning occupation/profession

Gender-indicative

Figure 1. The Continuum of Ninisite Usernames' Identity Markers 
Using a grounded theory approach, different levels of analyses were applied to the data. The main findings of the study are summarized below.

\section{Linguistic Analysis}

The first line of analysis was carried out on the linguistic level, focusing on word and phrase types. Nearly half of the usernames adopted by Ninisite users included anthroponyms (52.4\%), which encompasses either nonfamous characters, like the users' own real names, their loved ones, or a desired real name. Appellatives $(17.3 \%)$ and usernames with some adjectives in them (15.1\%) were two other categories of usernames. Other subcategories included onomatopoeic words $(0.24 \%)$ and sentences $(5.3 \%)$. About $10 \%$ of the usernames could not be decoded or categorized under any of the categories identified. A roughly similar result was obtained by Stommel (2007), where she found that "commonly known names" and "other names" were the major categories. While the types of words and phrases found were, to a great extent, identical, there were differences in terms of the categories. For instance, onomatopoeic words and sentences were two categories which were not identified by Stommel (2007). Exclamations was a category pinpointed in her study, and not identified in the data used in this study.

\section{Thematic Analysis}

Another line of results was obtained through a thematic analysis of the usernames. The recurrent themes in the usernames included gender, religion/ideology, sense of belonging, ethnicity, occupation, being humorous, and a sense of uniqueness. Some of these themes were identified in previous studies as well. The themes identified by Stommel (2007) included feminine, childish, self-confident, distinctive, and depressed. Feminine and distinctive were also represented by some of the usernames adopted by Ninisite users, which were labeled as "femininity" and "uniqueness." Shebanova and Yablonska (2019), who had carried out an analysis of the usernames adopted by the users of an eating disorder forum, identified exotic and decorative names, metaphorical and mysterious usernames, mythical and fantasy characters, destructive images, and names reflecting bodily status. The "famous character" theme identified in this study can be considered as similar to the mythical and fantasy characters in the study by Shebanova and Yablonska (2019). However, some of the themes like religion/ideology were unique to the sociocultural context of Iran.

An overlap between the themes could also be observed. Gender was the most frequently used theme, but it also was versatile in terms of collocating with other themes and creating novel constructions. This led to an overlap between the themes characterizing the usernames. For instance, gender plus uniqueness led to a username like فاطمه لاكجرى /Fatemeh lukcheri/, meaning "the luxurious Fatima." Gender plus occupation were traceable in the username 


\section{ADOPTED BY FEMALE USERS}

"Ms. Chemist."Alternately, gender was also juxtaposed with ethnicity to create / دختر كورد /Dokhtar-e- kord/, "Kurd girl."

These findings can help obtain a better perception of the users' worldviews and, as a result, how they interact with other users. The results can also be beneficial to the website administrators in terms of adapting and personalizing their website content, and even advertisement, to their users' attributes. People involved in business and marketing can take advantage of these identity-related cues in order to link their market brands with features of the users' social identities like gender, ethnicity, and consumption values (Wang et al., 2019). Future research can investigate if a change can be traced chronologically, meaning if the proportion of each of these themes which feed and contribute to the adopted usernames varies across time.

If access to demographic information of all users was available, an analysis of the relationship between age, residential area, level of education, marital status, and so forth of the users and the usernames they adopt could be very revealing. As Hassa (2012) contends, usernames are part of a complex naming practice, functioning as foundations for identity construction, projection, and mutation which may be an indicator of social, cultural, and political, patterns in context. 


\section{Acknowledgments}

The author would like to thank the reviewers for their constructive feedback.

\section{Conflict of Interest Disclosure}

The author reports no conflicts of interest.

\section{Funding}

The author reports no sources of funding for this study.

\section{Research Ethics Statement}

The study was carried out in accordance with the research ethics guidelines of the author's affiliated university. The data analyzed in the current study was publicly available and explicity allowed for analysis as part of research. 


\section{ADOPTED BY FEMALE USERS}

\section{References}

Aggarwal, C. (2016). An introduction to recommender systems. In C. Aggarwal (Ed.), Recommender systems (1-28). Springer International Publishing.

Aldrin, E. (2014). Choosing a name = choosing identity? Towards a theoretical framework In J. Tord Donada (Ed.), Names in daily life: Proceedings of the XXIV ICOS International Congress of Onomastic Sciences, Barcelona.

Aleksiejuk, K. (2016a). Pseudonyms. In C. Hough, \& D. Izdebska (Eds.), The Oxford handbook of names and naming (pp. 438-453). Oxford University Press.

Aleksiejuk, K. (2016b). Internet personal naming practices and trends in scholarly approaches. In G. Puzey, \& L. Kostanski (Eds.), Names and naming: People, places, perceptions and power (pp. 5-17). Multilingual Matters.

Aleksiejuk, K. (2017). Names on the Internet: Towards electronic socio-onom@ stics [Doctoral dissertation, University of Edinburgh]. ERA. http://hdl. handle.net/1842/23441

Alford, R. D. (1987). Naming and identity: A cross-cultural study of personal naming practices. HRAF Press.

Badrinarayanan, V. A., Sierra, J. J., \& Martin, K. M. (2015). A dual identification framework of online multiplayer video games: The case of massively multiplayer online role playing games (MMORPGs). Journal of Business Research, 68(5), 1045-1052. https://doi.org/10.1016/j.jbusres.2014.10.006

Baxter, J. A. (2008). Feminist post-structuralist discourse analysis: a new theoretical and methodological approach? In: K. Harrington, L. Litosseliti, H. Sauntson, \& J. Sunderland (Eds.) Gender and language research methodologies (pp. 243-255). Palgrave Macmillan.

Bucholtz, M., \& Hall, K. (2005). Identity and interaction: A sociocultural linguistic approach. Discourse Studies, 7(4-5), 585-614. https://doi. org/110.1177/1461445605054407

De Hoyos, B. (2020, November 27). How to create the perfect screen/username. Lifewire. https://www.lifewire.com/create-perfect-screen-name-1949903

Foucault, M. (1972). The archaeology of knowledge and the discourse on language. Pantheon Books.

Foucault, M. (1978). The history of sexuality. Penguin Books.

Grasmuck, S., Martin, J., \& Zhao, S. (2009). Ethno-racial identity displays on Facebook. Journal of Computer-Mediated Communication, 15, 158-188. https://doi.org/10.1111/j.1083-6101.2009.01498.x

Hämäläinen, L. (2013). Usernames in the online gaming community Playforia. In P. Sjöblom, T. Ainiala, \& U. Hakala (Eds.), Names in the economy: Cultural prospects (pp. 214-228). Cambridge Scholars.

Hassa, S. (2012). Projecting, exposing, revealing self in the digital world: Usernames as a social practice in a Moroccan chatroom. Names, 60(4), 201-209. https:// doi.org/10.1179/0027773812Z.00000000031

Jönsjö, J. (1979). Middle English nicknames: I. Compounds. CWK. 
Kersten, S., \& Lotze, N. (2020). Creating a self-image: Face-work and identity construction online. Journal for Media Linguistics, 2(2), 123-156. https:// doi.org/10.21248/jfml.2019.20

Kersten, S., \& Lotze, N. (2021). Anonymity and authenticity on the Web: Towards a new framework in internet onomastics. Internet Pragmatics, 5(1), 38-65. https://doi.org/10.1075/ip.00074.ker

Lam, W. (2004). Second language socialization in a bilingual chat room: Global and local considerations. Language Learning \& Technology, 8(3), 44-65.

Manago, A. M., Graham, M. B., Greenfield, P. M., \& Salimkhan, G. (2008). Selfpresentation and gender on MySpace. Journal of Applied Developmental Psychology, 29, 446-458. https://doi.org/10.1016/j.appdev.2008.07.001

Memari, M., Zalpour, A., \& Zia, M. (2017). An analysis of social presence and cognitive presence in discussion forum. Journal of Research in Applied Linguistics, 8, 299-303. https://doi.org/10.22055/rals.2017.12934.

Michikyan, M., Subrahmanyam, K., \& Dennis, J. (2015). A picture is worth a thousand words: A mixed methods study of online self-presentation in a multiethnic sample of emerging adults. Identity, 15(4), 287-308. https://doi. org/10.1080/15283488.2015.1089506

Olivier, J. (2014). Twitter usernames: Exploring the nature of online South African nicknames. Nomina Africana, 28(2), 51-74.

Prentice, C., Han, X.Y., Hua, L. L., \& Hu, L. (2019). The influence of identitydriven customer engagement on purchase intention. Journal of Retailing and Consumer Services, 47(2), 339-347. https://doi.org/10.1016/j. jretconser.2018.12.014

Rahmani (2021, April 27). A conversation with executive manager of Ninisite. Shanbemag. https://shanbemag.com/conversation-with-executive-managerninisite/\#comments.

Rodan, D., Uridge, L., \& Green, L. R. (2010). Using nicknames, pseudonyms and avatars on HeartNET: A snapshot of an online health support community. In Proceedings of Australian and New Zealand Communication Association Conference 2010. Australian and New Zealand Communication Association.

Schlobinski, P., \& Siever, T. (Eds.). (2018). Nicknamen international: Zur namenwahl in sozialen medien in 14 sprachen [International nicknames: On name choice on social media in 14 languages]. Peter Lang.

Shafie, L., Nayan, S., \& Osman, N. (2012). Constructing identity through Facebook profiles: Online identity and visual impression management of university students in Malaysia. Procedia-Social and Behavioral Sciences, 65, 134-140. https://doi.org/10.1016/j.sbspro.2012.11.102

Shebanova, V., \& Yablonska, T. (2019). Nickname as a means of linguistic selfpresentation in the Internet of people with eating disorders. Psycholinguistics, 25(1), 409-430.

Silva, R. R., \& Topolinski, S. (2018). My username is IN! The influence of inward vs. outward wandering usernames on judgments of online seller 


\section{ADOPTED BY FEMALE USERS}

trustworthiness. Psychology \& Marketing, 35(4), 307-319. https://doi. org/10.1002/mar.21088

Silva, R. R., Chrobot, N., Newman, E. Schwarz, N. \& Topolinski, S. (2017). Make it short and easy: Username complexity determines trustworthiness above and beyond objective reputation. Frontiers in Psychology 8: 2200. https://doi.org/10.3389/fpsyg.2017.02200

Sjöblom, P. (2006). Toiminimen toimenkuva: suomalaisen yritysnimistön rakenne ja funktiot [A firm name's job description. The structure and function of Finnish company names]. Suomalaisen Kirjallisuuden Seura,

Stommel, W. (2007). Mein Nick bin ich! Nicknames in a German forum on eating disorders. Journal of Computer-Mediated Communication, 13(1), 141-162. https://doi.org/10.1111/j.1083-6101.2007.00390.x

Subrahmanyam, K., Greenfield, P. M.,\& Tynes, B. (2004). Constructing sexuality and identity in an online teen chat room. Journal of Applied Developmental Psychology, 25(6), 651-666. https://doi.org/10.1016/j.appdev.2004.09.007

Subrahmanyam, K., Smahel, D., \& Greenfield, P. (2006). Connecting developmental constructions to the Internet: Identity presentation and sexual exploration in online teen chat rooms. Developmental Psychology, 42, 395-406. http:// dx.doi.org/10.1037/0012-1649.42.3.395

Subramanian, M. (2010). New modes of communication: Web representations and blogs: United States: South Asians. In S. Joseph (Ed.), Encyclopedia of women and Islamic cultures. Brill Online.

Tynes, B. M., Garcia, E. L., Giang, M. T., \& Coleman, N. E. (2011). Racial landscape of social networking sites: Forging identity, community, and civic engagement. Journal of Law and Policy for the Information Society, 7, 1-30.

Wang, H., Yuan, H., Li, X.,\& Li, H. (2019). The impact of psychological identification with home-name stocks on investor behavior: An empirical and experimental investigation. Journal of the Academy of Marketing Science, 47(2), 1131-1130. https://doi.org/10.1007/s11747-019-00677-3

Weedon, C. (1997). Feminist practice and poststructuralist theory (2nd ed.). Blackwell.

Xu, X., Huang, H., Jiang. T., \& Zou, Y. (2020). WeChat usernames: An exploratory study of users' selection practices. Names, 68(3), 156-168. https://doi.org/1 0.1080/00277738.2020.1758493

Yoshida, M., Heere, B., \& Gordon, B. (2015). Predicting behavioral loyalty through community: Why other fans are more important than our own intentions, our satisfaction, and the team itself. Journal of Sport Management, 29(3), 318-333. https://doi.org/10.1123/jsm.2013-0306

Zhou, F., Mou, J., He, M. \& Kim, J. (2021). Nicknames as identity badges: How self-reflective nicknames can facilitate users' online social interactions. Journal of Retailing and Consumer Services, 60, 102459. https://doi. org/10.1016/j.jretconser.2021.102459 